\title{
Factories, Movies, and Sport Science
}

Innovative Australian running coach Percy Cerutty prepared Herb Elliot for the 1960 Rome Olympic Games with little, if any, external support. ${ }^{1}$ As a true amateur athlete, Elliot surprised the world by winning an Olympic gold medal with a world-record time of 3:35.6 in the 1500-m event. Australia was awarded 8 gold medals in Rome, but the Soviet Union with their governmentfunded athletes reigned supreme, winning gold 43 times. The Soviet Olympic nation was the top medal-winning team for 6 of its 9 Summer Olympic Games. ${ }^{2}$

Coaches and sport scientists from around the world studied the Soviet "gold-medal-winning factory." In an attempt to increase international competitiveness, many countries built their own centralized elite sport centers. ${ }^{2}$ East Germany learned from the Soviet Union, and with heavy state funding, exceptional facilities, committed coaching, and sport science support, the country became an Olympic-medal-winning powerhouse from 1976 to 1988.

The Australian Institute of Sport opened in 1981 and in many ways emulated Soviet Union and East German medal-winning factories complete with scientific departments that focused on facilities, coach education, talent selection, and the "secret weapon"sport science. At the Australian Institute of Sport, physiology, psychology, nutrition, biomechanics, physical therapies, and sports medicine were encouraged to specialize and focus on safe, legal, and effective strategies that could provide a performance advantage. Laboratories were built, scientists hired, and athlete assessment and development methodologies refined, all with the objective of producing Olympic gold medals.

In the lead-up to the Sydney 2000 Olympic Games, something interesting happened at the Australian Institute of Sport. The Olympic Athlete Program (OAP) was formed, and funding was provided for "special projects" specifically designed to help athletes win. The OAP projects were often different in focus and format from traditional sport science research projects. The OAP initiatives were often newsworthy, interesting to coaches, and managed more like the making of a movie than refining the efficiency of a factory. High-performance managers worked like film producers, coaches worked like film directors, athletes were treated like actors, and sport scientists worked together, embracing high-tech solutions for relevant challenges. The process was in some ways analogous to a special effects studio used in a bigbudget movie with tight deadlines, high-tech multidisciplinary input, and a high-energy environment.

Australian projects in the lead-up to the 2000 Olympic Games were sometimes secretive, and sport scientists were not encouraged or directly rewarded for publishing findings. As a result, highly relevant and impactful initiatives such as training-venue reconnaissance, talent identification, aerodynamic assessment of equipment, and minimization of travel fatigue took place with potential medalwinning athletes. But, scientists quickly discovered that although meaningful, these OAP projects were far more difficult to publish.

Fortunately, International Journal of Sports Physiology and Performance emerged as one of the few sport science journals to recognize the importance of these ambitious, often descriptive field studies with elite athletes. One advantage of OAP-funded projects was that research was often conducted by sport scientists, who worked with coaches daily, embedded in the sport and could therefore quickly translate findings into practice. The conflict which emerged for sport scientists was whether they should commit to highly relevant projects that coaches and athletes endorsed or stay with more traditional research questions and experimental designs that could ultimately lead to publications in prestigious journals. For sport scientists employed by universities, the concept of "publish or perish" is, and has always been, influential. As a result, many talented scientists interested in sportrelated research make the decision to focus on research topics that lead to high-impact publications. ${ }^{3}$

Research by experienced scientists working in highly structured government-directed gold-medal factories is often heavily influenced by support from within the scientists' scientific discipline. Research projects can focus on topics such as environmental physiology, training methodology, demands of competition, benefits of nutritional supplements, and fitness assessment. It is common for research to be completed in partnership with universities, adopt traditional experimental designs, and use student athletes as subjects. Funding for these projects is generally awarded based on perceived importance of the research question, experimental design, and a scientist's track record (eg, publication history).

In contrast, when funding for special projects requires coach support and athlete buy-in, the work and outcomes must be highly relevant to the sporting program involved. Successful projects are often multidisciplinary in nature and involve elite athletes, and findings can quickly be implemented. Examples of applied research focusing on topics interesting to coaches include recovery from fatigue, ${ }^{4}$ timing of meals for optimal performance, ${ }^{5}$ and the physiological makeup of a Tour de France champion. ${ }^{6}$ Unfortunately, these topics are only interesting to a limited group of sport scientists, and even with flagrant "self-citing," it can be difficult for this type of research to generate high citations. On the other hand, when topics of interest to elite athletes (eg, high-intensity interval training) are investigated with nonathletes from a community health and wellness perspective, a publication can attract the kind of attention that can keep a professor employed. ${ }^{7}$ As a footnote, many talented sport scientists working in universities have made the decision to end research focused on elite sport to improve research impact, citations, and job security.

As the industry of sport science transitions into smaller collaborative teams of specialists working with formally trained, tech-savvy coaches conforming to timelines leading up to the World Championships or Olympic Games, there could be advantages to rethinking the best analogy for an ideal organizational structure that attracts and supports exceptional scientists who can make a meaningful contribution.

Perhaps a relevant perspective for Olympic centers of excellence comes from the film industry, where there has been "a shift away from integrated production and toward cooperative relationships among independent organizations." 8 The concept of performance-science units in elite sport working like special effects studios could be relevant and inspiring. In many special effects studios, a relatively large collection of PhDs in specialties such as computational fluid 
dynamics, computer vision, astrophysics, and mathematics work together adhering to strict timelines under the leadership of the director of the movie with the goal of enhancing the overall production. Research and iterative problem solving facilitate innovative solutions to complex problems in a relevant and timely manner, sometimes leading to interesting high-impact publications. ${ }^{9}$

The past tells us that medal-winning factories with multiple sport science departments can be relevant to sport in many ways, but perhaps the movie industry can teach sport science about the best ways to harness inspiration and creativity and deploy coordinated, multidisciplinary productions. Many wonderful movies have been made about sport (ie, Rocky, Remember the Titans, The Last Dance). Maybe the ultimate organization for supporting coaches, elite athletes, and sport scientists will combine organizational features of a gold-medal-winning factory with an awardwinning movie studio. Top scientists could then combine higher impact traditional research opportunities with innovative, unique, and inspiring projects that help athletes win.

To develop a complete mind: Study the science of art; Study the art of science. Learn how to see. Realize that everything connects to everything else.

—Leonardo da Vinci

Shona L. Halson, IJSPP Associate Editor, Australian Catholic University, Australia

David T. Martin, Australian Catholic University, Australia

\section{References}

1. Sims G. Why Die? The Extraordinary Percy Cerruty, 'Maker of Champions.' Sydney, Australia: Lothian Books.

2. Seppanen P. The Olympics: a sociological perspective. Int Rev Sociol Sport. 1984;19(2):113-127. doi:10.1177/101269028401900202

3. Buchheit M. Whom do we publish for? Ourselves or others? Int $J$ Sports Physiol Perform. 2020;15(8):1057-1058. PubMed ID: 32846409 doi:10.1123/ijspp.2020-0656

4. Vaile J, Halson S, Gill N, Dawson B. Effect of hydrotherapy on recovery from fatigue. Int J Sports Med. 2008;29(7):539-544. PubMed ID: 18058595 doi:10.1055/s-2007-989267

5. Hawley JA, Burke LM. Effect of meal frequency and timing on physical performance. Br J Nutr. 1997;77(suppl):S91-S103. doi:10. 1079/BJN19970107

6. Martin DT, Quod MJ, Gore CJ, Coyle EF. Has Armstrong's cycle efficiency improved? J Appl Physiol. 2005;99(4):1628-1629; author reply 1629. doi:10.1152/japplphysiol.00507.2005

7. Gibala MJ, Little JP, Macdonald MJ, Hawley JA. Physiological adaptations to low-volume, high-intensity interval training in health and disease. J Physiol. 2012;590(5):1077-1084. PubMed ID: 22289907 doi:10.1113/jphysiol.2011.224725

8. Robins JA. Organization as strategy: restructuring production in the film industry. Strateg Manage J. 1993;14(suppl):103-118. doi:10. 1002/smj.4250140909

9. James O, Tunzeimann E, Franklin P, Thorne K. Gravitational lensing by spinning black holes in astrophysics, and in the movie Interstellar. Classical Quant Grav. 2015;32(5):1-41. 